\title{
Pulmonary cell populations in recipients of bone marrow transplants with interstitial pneumonitis
}

\author{
HEATHER J MILBURN, L W POULTER, H G PRENTICE, R M DU BOIS \\ From the Departments of Thoracic Medicine, Immunology, and Haematology, Royal Free Hospital School of \\ Medicine, London
}

ABSTRACT The immunological basis of the inflammatory response in the lungs of patients with ${ }^{\times}$ pneumonitis after bone marrow transplantation has been investigated by means of bronchoalveolar lavage. Ten episodes of pneumonitis associated with cytomegalovirus and nine episodes due to ir various other infectious and non-infectious causes were investigated in 16 patients (three patients had 0 two episodes of pneumonitis). Total lavage cell counts and differential cell counts were determined 9 and compared with results from normal control subjects. In most patients with pneumonitis the total $\vec{c}$ cell yield was greater than normal (mean 6.8 (SD 6.0) $\times 10^{5} \mathrm{cells} / \mathrm{ml}$; normal 1-2 $\left.2 \times 10^{5} \mathrm{cells} / \mathrm{ml}\right)$. The percentage distribution of these cells was 71.9 (17) macrophage like cells, $24 \cdot 1$ (15.8) lymphocytes, 5.0 $(5.0)$ polymorphonuclear cells, and $0.7(1.0)$ eosinophils. None of the patients had peripheral $\infty$ lymphocytosis despite the increased number of lymphocytes in the lavage fluid. Further analysis of the lymphocyte population using monoclonal antibodies with immunocytochemical techniques showed that B cells were generally present in normal proportions, whereas the proportion of cells expressing T lymphocyte markers (CD2 $\left.{ }^{+}, \mathrm{CD5}^{+}, \mathrm{CD} 8\right)$ were reduced in nine out of 19 cases. In 10 of the 19 episodes there were substantial numbers of cells expressing none of the B or T cell antigens $\mathbb{D}$ studied ("null" cells). These abnormalities bore no relation to survival. The total cell yield, the $\overrightarrow{\vec{P}}$ proportion and number of lymphocytes, and the proportion and number of $T$ cells in the $\frac{O}{3}$ bronchoalveolar lavage fluid were all lower in the group with cytomegalovirus infections than in those with pneumonitis from other causes. These results suggest that the pneumonitis in recipients of bone marrow transplants is associated with a local immune response despite the fact that the individuals are otherwise immunosuppressed.

\section{Introduction}

Pulmonary complications are a major cause of morbidity and mortality in bone marrow transplant recipients $s^{1-4}$ and there is a particularly high incidence of infection with opportunist pathogens such as cytomegalovirus and Pneumocystis carinii. ${ }^{1-4}$ Such patients have been rendered immunologically incompetent by their disease, by the treatment required to attain remission, and later by pretransplantation conditioning, which includes total body irradiation, all of which may contribute to the high incidence of respiratory infections. We have investigated a group of recipients of bone marrow transplants with clinical

Address for reprint requests: Dr Heather J Milburn, Department of Thoracic Medicine, Royal Free Hospital School of Medicine, London NW3 2QG.

Accepted 12 April 1989 evidence of interstitial pneumonitis, ${ }^{5}$ to characterise any pulmonary cellular response and to see whether specific differential cell patterns could be identified that would be useful for diagnosis and for predicting 오 outcome. We have used bronchoalveolar lavage to $\triangle$ obtain samples of cells from the lower respiratory tract and immunocytological studies with monoclonal N antibodies to characterise the lymphocyte populations present.

\section{Methods}

\section{PATIENTS}

We investigated 16 recipients of bone marrow depleted of T cells. All had received allogeneic transplants as treatment for haematological malignancies. Two had $\overrightarrow{\mathbb{D}}$ acute lymphoblastic leukaemia, seven acute myeloid $\underset{\mathbb{D}}{\stackrel{\Omega}{\alpha}}$ leukaemia, and seven chronic granulocytic leukaemia. 을 All patients were given total body irradiation with an 
average dose to the lungs of $670-830 \mathrm{cGy}$ as part of their pretransplant conditioning. Eleven patients were male and five were female and their ages ranged from 16 to 46 (median 29) years. Only one patient smoked. Most patients developed pulmonary problems 40-120 days after transplantation; but three patients developed pneumonitis more than a year afterwards. Three patients developed two episodes of pneumonitis, both of which have been included in this study. Thus a total of 19 episodes of pneumonitis were investigated. In addition, 11 normal control subjects (three of whom smoked) had bronchoscopy and lavage.

\section{CLINICAL FEATURES}

All patients presented with shortness of breath and fever and 10 had a dry cough. Local changes were observed on the chest radiograph in 10 episodes of pneumonitis and diffuse changes in eight; the chest radiograph was normal in one episode. Pulmonary function tests, performed during 15 episodes of pneumonitis, showed reduced values for carbon monoxide transfer in all patients, including the patient with a normal chest radiograph. Pulmonary function could not be measured during episodes of pneumonitis, in which patients were isolated in reverse barrier nursing conditions. Blood gas tensions were not measured routinely, as most patients had few platelets $\left(<20 \times 10^{9} / 1\right)$. We found that acute breathlessness was the most important indicator of underlying pulmonary disease.

\section{SAMPLE COLLECTION}

Lavage was performed with a BFTI fibreoptic bronchoscope. The upper airways were anaesthetised with a $10 \%$ lignocaine topical spray and $2 \mathrm{ml}$ of $4 \%$ lignocaine were applied to the vocal cords under direct vision. Aliquots of $2 \%$ lignocaine were used to anaesthetise the lower respiratory tract. Supplemental oxygen was administered at a rate of 4 litres a minute during and four hours after the procedure. The tip of the bronchoscope was wedged into the orifice of a subsegmental bronchus of the middle lobe or lingula in patients with either a normal chest radiograph or diffuse radiological changes. Where the chest radiograph showed local changes the appropriate segment was lavaged. Lavage was performed with three $60 \mathrm{ml}$ aliquots of normal saline warmed to $37^{\circ} \mathrm{C}$ and buffered to $\mathrm{pH} 7.4$ by the addition of 175 microequivalents of sodium bicarbonate to $500 \mathrm{ml}$ normal saline. Each aliquot was aspirated immediately after its instillation and collected in silicon coated glass bottles maintained at $4^{\circ} \mathrm{C}$.

LAVAGE FLUID DIAGNOSES

In 10 cases cytomegalovirus was detected by both conventional cell culture and the detection of early antigen fluorescent foci. ${ }^{6}$ The diagnoses made in the remaining episodes of pneumonitis are outlined in table 1.

\section{PROCESSING LAVAGE SAMPLES}

All lavage samples were investigated for the presence of bacteria (including mycobacteria), fungi, protozoa, and viruses by standard microscopy and culture. In addition, the total cell count was determined from an aliquot of untreated lavage fluid in a modified Neubauer haemocytometer, and viability was assessed by cellular exclusion of trypan blue $(>70 \%$ in each case). Mucus strands were aspirated from the lavage fluid, which was then centrifuged at $350 \mathrm{~g}$ for 10 minutes; the supernatant was decanted. The cell pellet was washed twice in phosphate buffered saline $(\mathrm{pH}$ 7.2) and the cell suspension adjusted to a final concentration of $3 \times 10^{5} \mathrm{cells} / \mathrm{ml}$. Aliquots of this suspension, containing about $3 \times 10^{4}$ cells, were used to make cytospin preparations in a Shandon Cytospin II (Shandon Instruments, Runcorn). The cytospin preparations were air dried for one hour at room temperature, fixed in a chloroform:acetone mixture (1:1) for 10 minutes, air dried again, wrapped in cling film, and stored at $-20^{\circ} \mathrm{C}$ for future use. Differential cell counts were performed on cytospin preparations stained with May-Grünwald-Giemsa.

Table 1 Specific pulmonary diagnoses made by bronchoalveolar lavage

\begin{tabular}{|c|c|c|}
\hline Diagnosis & $\begin{array}{l}\text { First episode } \\
\text { of pneumonitis } \\
\text { (number) }\end{array}$ & $\begin{array}{l}\text { Second episode } \\
\text { of pneumonitis } \\
\text { (number) }\end{array}$ \\
\hline $\begin{array}{l}\text { Cytomegalovirus alone } \\
\text { Cytomegalovirus and }\end{array}$ & 6 & 1 \\
\hline $\begin{array}{l}\text { Pneumocystis carinni } \\
\text { Cytomegalovirus and }\end{array}$ & 2 & - \\
\hline Cryptosporidium & - & 1 \\
\hline Pneumocystis carinii & 1 & - \\
\hline Candida albicans & 1 & - \\
\hline Slaphylococcus aureus & 1 & 1 \\
\hline No infectious agent isolated & 4 & - \\
\hline
\end{tabular}

Table 2 Total cell counts and lymphocyte numbers (mean $(S D)$ ) in lavage fluid from patients who recovered from pneumonitis and those who died

\begin{tabular}{|c|c|c|c|}
\hline & \multirow{2}{*}{$\begin{array}{l}\text { Total cell count } \\
\left(\times 10^{s} \text { cells } / \mathrm{ml}\right)\end{array}$} & \multicolumn{2}{|l|}{ Lymphocytes } \\
\hline & & (\% total cells) & $\left(\times 10^{s}\right.$ cells $\left./ \mathrm{ml}\right)$ \\
\hline $\begin{array}{l}\text { Survived } \\
(\mathrm{n}=8) \\
\text { Died } \\
\quad(\mathrm{n}=11)\end{array}$ & $\begin{array}{ll}7 \cdot 3 & (5 \cdot 5) \\
6 \cdot 5 & (9 \cdot 0) \\
\text { NS } & \end{array}$ & $\begin{array}{ll}20.4 & (10.6) \\
26.5 & (19.2) \\
\text { NS } & \end{array}$ & $\begin{array}{ll}1 \cdot 2 & (0.8) \\
2 \cdot 2 & (2 \cdot 5) \\
\text { NS } & \end{array}$ \\
\hline
\end{tabular}




\section{IMMUNOCY TOCHEMISTRY}

Subpopulations of lymphocytes were identified with monoclonal antibodies by indirect immunocytochemical methods. ${ }^{7} \mathrm{~T}$ cells were identified with the monoclonal antibody cocktail RFT Mix (CD5, 8, 2), which is a mixture of RFT1, 8, and 11 (source Royal Free Hospital School of Medicine). B cells were identified by means of an RFB mix (CD21, 22), a cocktail of RFB3 and B6 (Royal Free Hospital School of Medicine). The number of cells expressing neither $T$ nor $B$ cell antigens was calculated and these were designated "null cells." Negative controls were performed by omitting the first layer monoclonal antibodies. Positive controls for all reagents used were routinely performed by reactions on human palatine tonsil (a tissue containing examples of all cell populations analysed) each time cytospin samples were investigated.

\section{QUANTIFICATION}

In each case random high power fields from cytospin preparations of each reaction were examined and the proportion of positive cells was noted. Three hundred cells were counted in each case. If no positive cells were detected, the count was recorded as $<1 \%$. The mean values of the proportion of cells in lavage fluid from each patient were calculated.

\section{STATISTICAL ANALYSIS}

The Wilcoxon rank sum test for non-parametric data was used to determine statistical significance.

\section{Results}

TOTAL CELL COUNT

The total cell count was extremely variable between individuals. Six patients yielded total numbers of cells within the range expected from the normal control data $\left(1-2 \times 10^{5}\right.$ cells $\left./ \mathrm{ml}\right)$, but the remainder yielded varying numbers up to 20 times the normal range. There was a difference $(p<0.05)$ between the total numbers of cells in patients with pneumonitis associated with cytomegalovirus (mean (SD) $3 \cdot 2$ (2.6) $\times 10^{5}$ cells $/ \mathrm{ml}$ ) and patients with pneumonitis where cytomegalovirus was not detected (mean $10.4(9.4) \times$ $10^{5}$ cells $/ \mathrm{ml}$ )- fig 1 . Only one of the patients with two episodes of pneumonitis showed a difference in total cell numbers on the two occasions.

\section{DIFFERENTIAL CELL COUNT}

The most striking findings in the differential cell counts were the greater proportion of lymphocytes in most patients than in the normal subjects and the smaller proportion of macrophages (fig 2). In the normal subjects $5 \cdot 82 \%$ (SD $5 \cdot 64 \%$ ) of cells in lavage fluid were lymphocytes compared with $24 \%$ (15.8\%) in the patients $(\mathrm{p}<0.001)$. Although patients with cytomegalovirus pneumonitis had a lower proportions? of lymphocytes $(19.5 \%(10.5 \%))$ than patients witho other causes of pneumonitis $(28.6 \%(21 \%)$, the dif-드 ferences were not significant. The proportion of polymorphonuclear cells was less variable and gen- $\mathbb{D}$ erally within the normal range, though four patients had increased numbers. Of these, one was infected"s with staphylococci, one with Pneumocystis carinii, one. with Candida albicans, and one with cytomegalovirus $\overrightarrow{\vec{\omega}}$ and cryptosporidia. There was no significant increase in the proportion of eosinophils found in any patient. The absolute numbers of lymphocytes present in the lavage fluid from patients was higher than those of: controls ( $p<0.001$, fig 3$)$, and higher $\left(2.8(2.54) \times 10^{5} \mathrm{~V}\right.$ cells $/ \mathrm{ml})$ in patients with other causes of pneumonitis than in those with cytomegalovirus pneumonitis $(0.75 \mathrm{O}$ $(0.95) \times 10^{5}$ cells $\left.\left./ \mathrm{ml}\right) ; \mathrm{p}<0.05\right)$. Most lymphocytes_ were large cells with morphological features typical of immature cells. Although the percentage of macro phages recovered from patients was lower than that from normal subjects, the absolute number was noto significantly different. In fact, the mean recovery of alveolar macrophages was higher than normal ino many of the patients with bone marrow transplant.

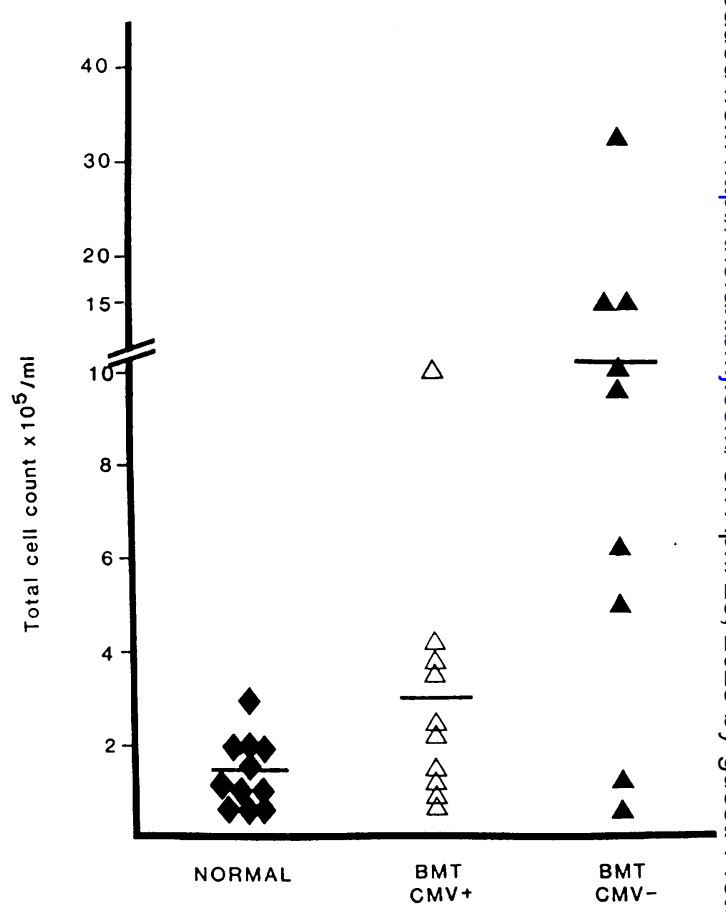

Fig 1 Total cell counts in lavage fluid of normal control subjects $(\diamond)$ compared with recipients of bone marrow transplants $(B M T)$ with pneumonitis, patients with cytomegalovirus $(C M V)$ in lavage fluid $(\triangle)$ and patients in whom no cytomegalovirus was detected $(\Delta)$. 
There was also an increase in absolute numbers of neutrophils in lavage fluid.

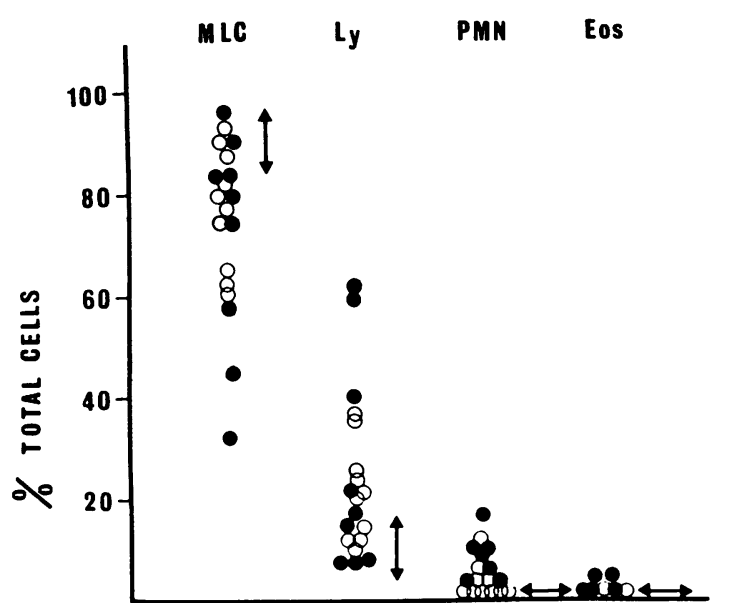

Fig 2 Differential cell counts in lavage fluid from patients with bone marrow transplants with pneumonitis.

Cytomegalovirus present in lavage fluid;

cytomegalovirus not isolated from lavage fluid; $\mid$ normal range; MLC-macrophage like cells; Ly-lymphocytes;

PMN-polymorphonuclear cells; Eos-eosinophils.

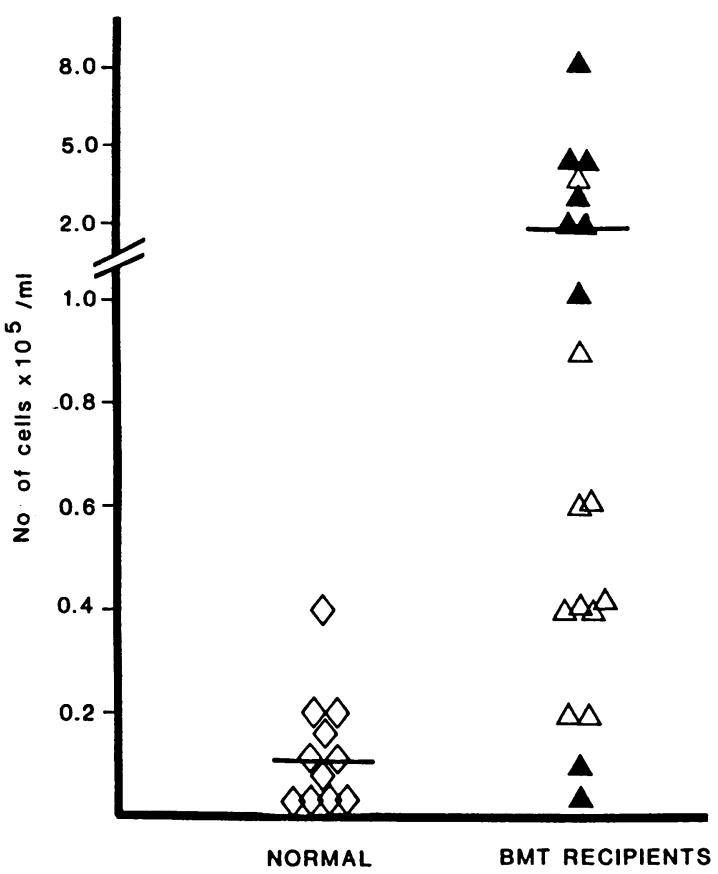

Fig 3 Absolute numbers of lymphocytes in lavage fluid from normal subjects and recipients of bone marrow transplants (BMT) with pneumonitis. $\triangle$ Cytomegalovirus present in lavage fluid; $\Delta$ cytomegalovirus not detected in lavage fluid.
SUBSETS OF LAVAGE FLUID LYMPHOCYTES

In most episodes (14/19) the proportion of $B$ cells in lavage fluid was normal (fig 4), whereas in nine of the 19 lavage samples the proportion of $T$ cells was reduced. In 10 episodes an appreciable number of lymphocytes ( $>8 \%$ ) (referred to as "null" cells) expressed neither B nor $\mathrm{T}$ cell surface markers. The presence of abnormal numbers of null cells did not correlate with time from transplantation, diagnosis, or survival.

\section{ANALYSIS OF PERIPHERAL BLOOD CELLS}

Peripheral blood taken at the time of bronchoscopy showed a mean total white cell count of 3.5 (SD 1.6) (range $0 \cdot 1-18.5) \times 10^{9} / 1$. Six patients had a normal total white cell count, one a raised count, and the remainder a below normal count; none had lymphocytosis. There was no relation between the peripheral white cell differential count and the type of cells recovered in the lavage fluid (data not shown).

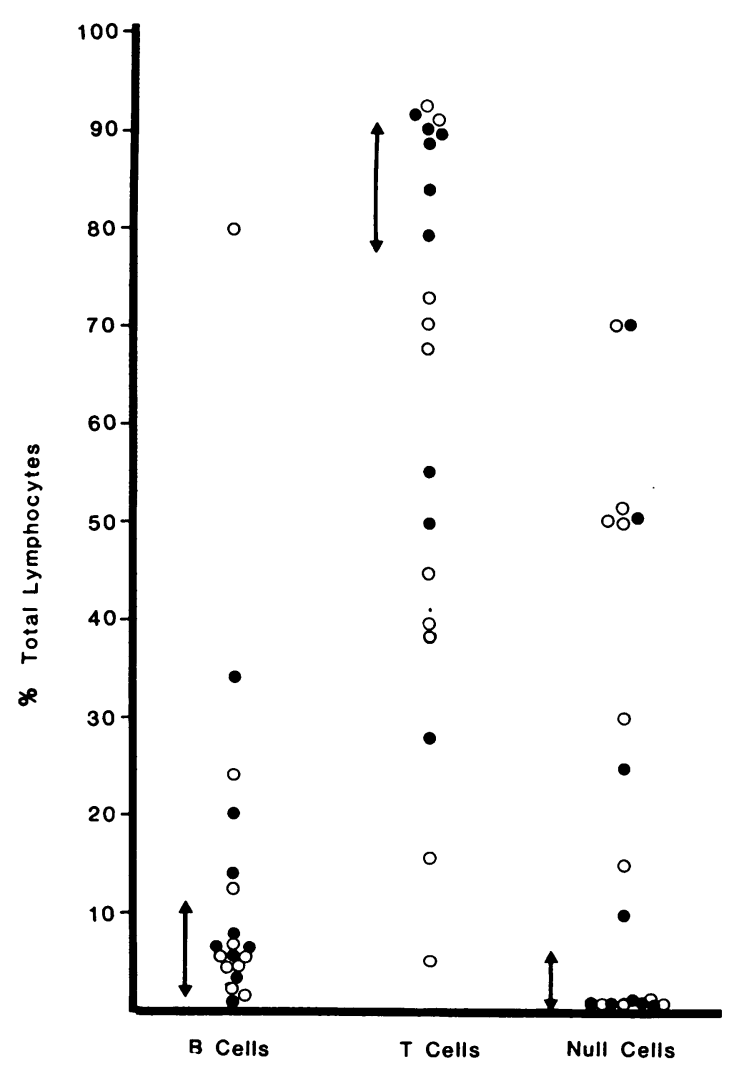

Fig 4 Proportion of $B$ cells, $T$ cells, and null cells in lavage fluid of recipients of bone marrow transplants with pneumonitis. $\bigcirc$ Cytomegalovirus present in lavage fluid; cytomegalovirus not isolated from lavage fluid; $\mid$ normal range. 
RELATION OF CELL POPULATIONS TO CLINICAL PICTURE AND SURVIVAL

The clinical presentation and extent of lung shadowing on chest radiograph showed no correlation with the counts of any of the cell populations in the lavage fluid. There was also no correlation between cell numbers and survival. Eight patients recovered from the initial episode of pneumonitis, though three developed a second infection. Eleven patients died (three during the second episode).

\section{Discussion}

It is well recognised that the lung is extremely susceptible to unusual infections and other insults during the six months after bone marrow transplantation..$^{-4}$ This may be due to systemic immunosuppression, a local effect of irradiation, or a specific defect in local pulmonary immunity. We have explored the latter possibility, using bronchoalveolar lavage to determine the type of cells present in the lower respiratory tract of recipients of bone marrow transplants with pneumonitis to see if the inflammatory cell populations correlated with specific diagnoses, clinical presentation, or prognosis.

The range of total cell counts in lavage fluid recovered from the lungs during the episodes of pneumonitis was wide, but the mean numbers were considerably greater than those from normal control subjects. Similar findings have been reported in patients with AIDS. ${ }^{8}$ The total cell count was not, however, diagnostic of any specific infection, though patients with cytomegalovirus associated pneumonitis yielded fewer total cells than those with pneumonitis where cytomegalovirus was not detected. Six of the patients with cytomegalovirus pneumonitis had total cell counts within the normal range. This finding is compatible with the possibility that patients failing to develop lymphocytosis may be the most susceptible to cytomegalovirus infection. Alternatively, the virus itself may be suppressing the patient's capacity to develop a local cellular immune response.

The total cell counts in lavage fluid did not reflect the peripheral cell counts, though only one patient developed pneumonitis before the peripheral white cell count had started to recover. The recovery of the peripheral white cell count after transplantation of $T$ cell depleted bone marrow has been studied by Favrot et al. ${ }^{9}$ The re-emergence of the host's ability to mount an inflammatory response clearly therefore must be contributing to the disease process in the lung in the presence of opportunist pathogens. Even in patients with AIDS with reduced numbers of lymphocytes (particularly $\mathrm{CD}^{+}$in peripheral blood) pneumonitis is characterised by lymphocytosis in lavage fluid. ${ }^{8}$ We cannot, however, assume that the immunological mechanisms underlying pneumonitis in recipients of $\times$ bone marrow transplants are the same as those $\vec{\Rightarrow}$ occurring in patients with AIDS. ${ }^{10}$

Most patients with pneumonitis had normal? proportions of B cells, but some patients, particularly $\frac{\bar{\sigma}}{\bar{c}}$ those with cytomegalovirus pneumonitis, had a lower $\frac{\widehat{\sigma}}{\bar{\sigma}}$ proportion of cells expressing the T cell markers $\mathrm{CD} 2, \stackrel{\mathrm{D}}{\mathrm{Q}}$ CD5, or CD8. In addition, 10 patients had lavage fluid $T$ cells that failed to express markers of either of these $\vec{\circ}$ populations. Possibly these cells are nevertheless B or $\mathrm{T}$ cells, but either express the appropriate markers at $\vec{\omega}$ such a low density on the cell surface that they were not? detected by our technique or represent a population of $\vec{x}$ immature cells that do not express these antigens. $f$ Consistent with this possibility, many of the lympho- $-v$ cytes seen appeared morphologically to be large blast like cells. Although these "null cells" were morphologically lymphoid, could they fall within a population of "small macrophages"? This possibility was dis- $\vec{c}$ counted by subsequent studies, in which we analysed the expression of other lymphocyte antigens on the lymphocyte subsets recovered from these patients $\mathbb{O}_{0}$ (paper in preparation).

The meaning of the lymphocytosis in lavage fluid is not clear. This occurred in patients with viral, bacterial, fungal, and protozoal infection and in patients in whom no infectious organism was isolated. There was no difference in proportions or absolute numbers $\stackrel{\mathbb{Q}}{\AA}$ of lymphocytes between survivors and non-survivors $\overrightarrow{\vec{P}}$ (table 2). It is clearly a local phenomenon and may as such represent an immune response to an infecting organism. Alternatively, as the lavage fluid lymphocytosis may be present without detectable infection it may represent disordered immunity, which in turn may be the reason why the lung becomes a target organ. Ethical considerations prevented us from per- -0 forming bronchoscopy on patients with bone marrow transplants who had no symptoms or signs of pneumonitis to investigate this possibility. Follow up bronchoscopies were not performed on patients aftero recovery from pneumonitis for similar reasons, so we do not know whether the lymphocytosis precedes theo infection or is the result of the infection and subsides on recovery.

Lymphocyte numbers are increased in the lavagen fluid from patients with tuberculosis, berylliosis, N extrinsic allergic alveolitis, and sarcoidosis. ${ }^{11-14} \mathrm{As}_{O}^{\mathrm{C}}$ immunological mechanisms are thought to have aprimary role in these conditions, the pneumonitis in these recipients of bone marrow transplant may wello? also result from a local immune response. The hypothesis that the pneumonitis results from the localo expression of an acquired immune response in aब systemically immunosuppressed patient is an intrigu- $\frac{?}{\mathbb{D}}$ ing one. The cause of this immune associated inflam- $\varrho$ mation remains unknown. It may be the result of a 
recurrent infection or infections or a response to alloantigens (as local graft versus host disease), or alternatively it may result from immunoregulatory dysfunction. Further phenotypic analysis of the lymphocytes in lavage fluid from patients with bone marrow transplant is being used to investigate these possibilities.

\section{References}

1 Buckner CD, Meyers JD, Springmeyer SC, et al. Pulmonary complications of marrow transplantation: Review of the Seattle experience. Exp Haematol 1984;12(suppl 15): $1-5$

2 Neiman PE, Reeves W, Ray G, et al. A prospective analysis of interstitial pneumonia and opportunistic viral infection among recipients of allogeneic bone marrow grafts. J Infect Dis 1977;136:754-67.

3 Meyers JD. Viral infections in marrow transplant recipients. Recent advances in bone marrow transplantation. New York: Liss, 1986:214.

4 Meyers JD, Fluornoy N, Thomas ED. Non-bacterial pneumonia after allogeneic marrow transplantation: a review of ten years' experience. Rev Infect Dis 1982; 4:1119-32.

5 Milburn HJ, Prentice HG, du Bois RM. Role of bronchoalveolar lavage in the evaluation of interstitial pneumonitis in recipients of bone marrow transplants. Thorax 1987;42:766-72.

6 Griffiths PD, Panjuani DD, Stirk PD, et al. Rapid diagnosis of cytomegalovirus infection in immunocom- promised patients by detection of early antigen fluorescent foci. Lancet 1984;ii:1242-5.

7 Mason DY, Abdulazy Z, Falini B, Stein H. In: Polak J, Van Noorden S, eds. Immunocytochemistry: practical applications in pathology and biology. Bristol: Wright, 1983:113.

8 White DA, Gellene RA, Gupta S, Cunningham-Rundles C, Stover DE. Pulmonary cell populations in the immunosuppressed patient: bronchoalveolar lavage findings during episodes of pneumonitis. Chest 1985; 88:352-9.

9 Favrot M, Janossy G, Tidman M, et al. T cell regeneration after allogeneic bone marrow transplantation. Clin Exp Immunol 1983;54:59-72.

10 Macher AM. Infection in the acquired immunodeficiency syndrome. In: Fanci AS (moderator). Acquired immunodeficiency syndrome: epidemiologic, clinical immunologic and therapeutic considerations. Ann Intern Med 1984;100:94-6.

11 Reynolds HY, Fulmer JD, Kazmierowski JA, Roberts WC, Frank MM, Crystal RG. Analysis of cellular and protein content of bronchoalveolar lavage fluid from patients with idiopathic pulmonary fibrosis and chronic hypersensitivity pneumonitis. $J$ Clin Invest 1977;59:165-75.

12 Hunninghake GW, Gadek JE, Kawanami O, Ferrans VJ, Crystal RG. Inflammatory and immune processes in the human lung in health and disease: evaluation by bronchoalveolar lavage. Am J Pathol 1979;97:149-98.

13 Crystal RG, Roberts WC, Hunninghake GW, Gadek JE, Fulmer JD, Line BR. Pulmonary sarcoidosis: a disease characterised and perpetuated by activated lung Tlymphocytes. Ann Intern Med 1981;94:73-94.

14 Merrill WW, Reynolds HY. Bronchial lavage in inflammatory lung disease. Clin Chest Med 1983;4:71-84. 